To the Editors:

\title{
Outcome of anastomotic urethroplasty in bulbomembranous urethral strictures
}

Poorly managed traumatic bulbomembranous urethral strictures could have a devastating effect on the quality of life. Until recently this problem was poorly managed in Sri Lanka, condemning some patients to lifelong suffering with unsettled lower urinary tract obstructive symptoms and infective complications. The commonest primary injury is pelvic fracture. A complete urethral rupture associated with pelvic fracture mostly ends up in a urethral stricture [1], demonstrable as a total discontinuity of the urethra in contrast urethrography. A segment of bulbomembranous urethra undergoes spongiofibrosis and gets replaced with fibrous tissue, so that less invasive treatment modalities such as urethral dilation and endoscopic incision of the stricture (optical urethrotomy) yield a poor outcome. Excision of the stricture followed by end-to-end anastomosis seems to be a logical solution to this problem in spite of its complexity and the higher demand on surgical skill [2]. There are no published local data on this technique. The present study describes the initial outcome of this procedure carried out by the author in a tertiary urological referral center.

The study comprises a retrospective review of 46 patients who underwent anastomotic urethroplasty from January 1997 to December 2001. All patients were males, between 7 and 58 years of age. Pelvic fractures (road traffic accidents in 36, falls in 5) was the cause in 41 patients. The others were inflammatory in origin compounded by blind instrumentation. Before referral several patients had undergone surgical procedures such as urethral dilation (8 patients), optical urethrotomy (12), railroading urethral realignment (5) and endoscopic realignment (4) without success. Thirty eight patients were with a long term surapubic cystostomy. Patients were scheduled for surgery 4 to 6 months after injury was assessed with basic renal function tests, ultrasound urodynamography, combined ascending and descending urethrography and urethroscopy (only when suspected to have multiple strictures). The procedure was carried out under general $(11 / 46)$ or spinal $(35 / 46)$ anaesthesia in an exaggerated lithotomy position. The bulbomembranous urethra was approached transperinealy (39/46) in combination with supra-pubic exposure (7/46). After dissecting and defining, the strictured segment (5-25 mm in length) was resected and end-to-end anastomosis was achieved in 42 patients. Due to technical difficulties a urethral pull-through technique was used in four patients [4]. A urethral catheter was in place for 10 to 14 days. Following the catheter removal and passage of urine, a blocked supra-pubic catheter was left as a safety valve for 3 months. Patients were asked to report immediately in case of poor urinary stream. Otherwise they were assessed by uroflowmetry in 6 to 12 weeks and post-operative urethrography in case of suspected repeat stricturing. The supra-pubic catheter was removed after 3 to 6 months in patients who did not show any evidence of stricture.

Thirty eight ( $82 \%$ ) patients were judged cured at the end of a follow up period of 8 to 60 months when there was no evidence of stricture recurrence. Eight patients had varying degrees of restenosis at the anastomotic site which needed regular optical urethrotomy and dilation (5/8), repeat urethroplasty (3/8) and Mitrofanoff appendicovesicostomy urinary diversion (1/8). Complications also included primary haemorrhage which required blood transfusion (3 patients), perineal haematoma, infection and wound dehiscence (1), erectile failure (5) and stress incontinence (3) and rectourethral fitula (1). Complication rates compared well with other studies [6].

The cure rates were encouraging in a condition which was notoriously difficult to manage because of marked fibrosis of the urethra. In traditionally used urethral dilation and endoscopic urethrotomy only one-third of strictures get cured and the subsequent urethroplasty of the failures would be technically more difficult as a result of increased periurethral fibrosis $[3,5]$. Although not universally accepted, local excision of the stenotic segment and end-to-end anastomosis seems to be the treatment of choice, with cure rates close to $100 \%$ in some studies [5]. While short $(<1 \mathrm{~cm})$, well aligned strictures would still respond to lesser procedures, with present experience we recommend anastomotic urethroplasty for recurrent (after two attempts of dilation or endourethrectomy), long and malaligned strictures. Our results also emphasise the fact that pelvic fractures associated with posterior urethral injury should be best managed initially with supra-pubic drainage followed by referral to a specialised unit for the management of the resulting stricture.

\section{References}

1. Lowe MA, Mason JT, Luna GK Maier RV, Copass MK, et al. Risk factors for urethral injuries in men with traumatic pelvic fractures. Journal of Urology 1988; 140: 506-7.

2. Micheli E, Raneri A, Peracchia G. End-to-end urethroplasty: Long term results. British Journal of Urology 2002; 90: 68-71.

3. Pansadoro V, Emiliozzi P. Internal urethrotomy in the management of anterior urethral strictures. Long-term followup. Journal of Urology 1996; 156: 73-5.

4. Turner-Warwick RT. Complex traumatic urethral strictures. Journal of Urology 1977; 118: 564-74. 


\section{Research letters}

5. Jakse G, Marberger H. Excisional repair of urethral stricture: Follow-up of 90 patients. Urology 1986; 27: 233-6.
6. Mundy AR. Results and complications of urethroplasty and its future. British Journal of Urology 1993; 71: 322-5.

Neville D Perera, Urological Surgeon, Department of Urology, The National Hospital of Sri Lanka, Colombo, Sri Lanka. Tel: +94 11 2778061, e-mail nevi603@sltnet.lk 